\title{
A prática de leitura dos alunos da escola de educação profissional Concórdia
}

\author{
The reading practice of students at the Concordia professional education school
}

\begin{abstract}
Morgana Sandi
Graduada em Biblioteconomia pela Universidade Comunitária da Região de Chapecó - UNOCHAPECÓ, Brasil.

E-mail: morgana.sandi@unochapeco.edu.br
\end{abstract}

\begin{abstract}
Orestes Trevisol Neto
Mestre em Ciência da Informação pela Universidade Federal de Santa Catarina - UFSC, Brasil. Bibliotecário da Universidade do Estado de Santa Catarina - UDESC, Brasil e Professor no curso de Biblioteconomia EaD da Universidade Comunitária da Região de Chapecó - UNOCHAPECÓ, Brasil.

E-mail: orestes_tn@hotmail.com
\end{abstract}

\section{Resumo}

Esta pesquisa busca responder como ocorre a prática de leitura entre os adolescentes vinculados aos cursos de Aprendizagem da Escola de Educação Profissional Concórdia O objetivo geral desta pesquisa foi analisar as práticas de leitura do público adolescente matriculado em cursos de Aprendizagem da Escola de Educação Profissional Concórdia. Como objetivos específicos buscou-se identificar qual é o nível de interesse dos adolescentes pela leitura; identificar quais são os seus hábitos e preferências de leitura; apontar quem são os agentes incentivadores da prática de leitura; apurar qual é o interesse dos adolescentes no tocante à utilização da biblioteca escolar. A pesquisa realizada foi quantitativa e a coleta de dados foi realizada por meio de um questionário impresso com 17 questões abertas, fechadas e de múltipla escolha, que foi aplicado para 161 alunos. Os resultados obtidos apontaram dados relevantes em relação aos hábitos de leitura dos adolescentes pesquisados, indicando que o número de leitores supera o de não leitores e que preferem a leitura de materiais impressos. Além disso, constatou-se que o livro é um dos materiais preferidos para leitura e os livros lidos são considerados de "literatura de massa". Entretanto, a pesquisa revelou que, apesar de haver biblioteca na escola em que estudam, a maior parte dos adolescentes não frequenta a biblioteca escolar com assiduidade.

Palavras-chave: Leitura. Biblioteca escolar. Adolescentes.

\begin{abstract}
This research seeks to answer how does the practice of reading among adolescents linked to the Learning courses of the School of Professional Education Concordia? The general objective of this research was to analyze the reading practices of the adolescent public enrolled in Learning courses of the School of Professional Education Concordia. Specific objectives were to identify the adolescents' level of interest in reading; identify your reading habits and preferences; to point out who are the incentive agents of reading practice; to find out what is the interest of the adolescents in the use of the school library. The research was quantitative and the data collection was done through the application of a printed questionnaire with 17 open, closed and multiple choice questions, which was applied to 161 students. The results obtained indicated relevant data regarding the reading habits of the adolescents surveyed, indicating that the number of readers surpasses that of non readers and that they prefer the reading of printed materials. In addition, the book is one of the preferred materials for reading and the books read are considered "mass literature". However, the research revealed that although there is a library in the school where they study, most adolescents do not attend the school library with assiduity.
\end{abstract}

Keywords: Reading. School library. Teenagers. 


\section{Introdução}

A adolescência compreende um período de constituição de um futuro adulto formador de opinião, que começa a perceber a vida em sociedade e a questionar as informações que lhes são apresentadas. Assim, a leitura figura como uma ferramenta capaz de contribuir para o entendimento e compreensão das informações, bem como para a formação de opinião crítica do indivíduo frente ao contexto social que se apresenta (SILVA; CUNHA, 2016).

Diante do exposto questiona-se: como ocorre a prática de leitura entre os adolescentes vinculados aos cursos de Aprendizagem da Escola de Educação Profissional Concórdia? Portanto, o objetivo geral da pesquisa é analisar as práticas de leitura de adolescentes matriculados nos cursos de Aprendizagem da Escola de Educação Profissional Concórdia. De maneira específica, foram delineados os seguintes objetivos: identificar qual é o nível de interesse dos adolescentes pela leitura; identificar quais são os hábitos e preferências de leitura dos adolescentes; apontar quem são para os adolescentes os agentes incentivadores da prática de leitura; apurar qual é o interesse dos adolescentes no tocante à utilização da biblioteca escolar.

Conhecer as preferências de leitura do público adolescente contribui para que bibliotecários(as) escolares possam compreender qual é a percepção da leitura aos olhos do adolescente, para o desenvolvimento de práticas desta que a apresentem como fonte de entretenimento (BOTO; BRAZ, 2017).

Ademais, conhecendo como o processo de leitura ocorre entre os adolescentes e quais são suas preferências, tais profissionais podem obter informações relevantes para o desenvolvimento de coleções com o propósito de atender aos anseios desse público. E, o mais importante, permitir que compreendam melhor o mundo que os cerca por meio da leitura. 


\section{Procedimentos metodológicos}

A pesquisa classificou-se como descritiva, quantitativa e aplicou a técnica de pesquisa bibliográfica e levantamento. Foi utilizado um questionário para a coleta de dados fundamentado na pesquisa Retratos da Leitura no Brasil ano de 2016, com o total de 17 perguntas, sendo abertas, fechadas e de múltipla escolha. As perguntas foram voltadas à definição do perfil do adolescente, o que pensa acerca da leitura, suas preferências de leitura, sua frequência e/ou utilização de bibliotecas e se recebeu algum estímulo para o desenvolvimento do hábito de leitura. O questionário foi aplicado no dia 30 de outubro de 2018, durante os períodos matutino e vespertino. As perguntas foram respondidas manualmente, em questionários impressos. Optou-se pela aplicação desta maneira para evitar transtornos na rotina escolar e não haver prejuízo em relação ao horário de aula e para garantir o maior número de questionários respondidos.

A pesquisa foi aplicada a alunos matriculados nos cursos de Aprendizagem, que objetivam a formação técnico-profissional de menores a partir de quatorze anos, através da integração entre o ensino oferecido pelos Serviços Nacionais de Aprendizagem e a atividade como menores aprendizes nas empresas contratantes (BRASIL, 2000). O universo da pesquisa é composto por 174 adolescentes na faixa etária entre 14 a 18 anos, que representam a totalidade de alunos matriculados nos cursos de Aprendizagem. Entretanto, responderam o questionário somente os alunos que estavam presentes na data da pesquisa, ou seja, 161 adolescentes, que equivale a $92,53 \%$ do universo da pesquisa. Destaca-se que o questionário foi realizado em uma instituição de ensino da cidade de Concórdia/SC, a qual foi atribuído o nome fictício de Escola de Educação Profissional Concórdia, para preservar a identidade da instituição e dos adolescentes pesquisados. 


\section{O processo de leitura}

Ler é uma prática que precede o exercício da leitura de um texto, é um processo que envolve vivências anteriores do leitor, nas palavras de Freire (2002, p. 11) "a leitura do mundo precede a leitura da palavra, [...]. A compreensão do texto a ser alcançada por sua leitura crítica implica a percepção das relações entre o texto e o contexto.”. Dessa forma, mesmo que o leitor saiba ler, o entendimento do que ele lê é reflexo de como compreende a realidade que o cerca. Partilha desta ideia Kleiman (2011, p. 13) ao afirmar que: "Pode-se dizer com segurança que sem o engajamento do conhecimento prévio do leitor não haverá compreensão.”

A leitura pode ser caracterizada, também, como o ato de decodificar os símbolos linguísticos presentes no texto, o que implica no prévio aprendizado do indivíduo. Além disso, é preciso que haja um processo de compreensão do que é lido, processo este, que é composto por fatores pessoais, culturais e cognitivos do leitor (MARTINS, 1994). Observa-se que a leitura depende de características subjetivas inerentes ao leitor para que este consiga não apenas decodificar o texto lido.

Kleiman (2011) afirma que uma criança durante a alfabetização lê devagar, ou seja, ela está fazendo o processo de decodificação, ao passo que o leitor adulto não decodifica, ele percebe as palavras como um todo e adivinha outras por meio de seu conhecimento anterior. Nesse sentido, destacam Koch e Elias (2010, p. 11) que:

\footnotetext{
A leitura é, pois, uma atividade interativa complexa de produção de sentidos, que se realiza evidentemente com base nos elementos linguísticos presentes na superfície textual e na sua forma de organização, mas requer a mobilização de um vasto conjunto de saberes no interior do evento comunicativo. (Grifos dos autores)
}

Logo, a preocupação com a formação de leitores críticos deve sempre ser considerada, pois quanto maior a frequência de leitura, mais o leitor desenvolve sua capacidade de interpretar e compreender o que lê, já que o ato de ler "[...] implica sempre percepção crítica, interpretação e "re-escrita" do lido [...]" (FREIRE, 2002, p. 21). Assim, a cada leitura de um mesmo texto o leitor poderá ter um novo entendimento em relação ao que leu, ainda que as variantes sejam mínimas (MARTINS, 1994).

Conforme Kleiman (2011), depois de realizada a leitura, o ser humano não consegue memorizar o texto lido em sua integralidade, ou seja, o texto literal, mas consegue lembrar as “inferências" feitas durante a leitura, pois tais "inferências" estão vinculadas ao conhecimento prévio do leitor frente ao assunto e também decorre de seu conhecimento de mundo. 
Ler não é apenas decodificar os símbolos presentes no texto, é um processo que demanda das experiências pessoais e leitoras. A leitura também é um exercício que depende da atividade cognitiva de quem lê, para então, haver a compreensão da mensagem decodificada e, com isso, atribuir sentido ao que foi lido.

A leitura é um instrumento que permeia todo o contexto educacional, por meio desta o aluno desenvolve capacidades que podem ser úteis para a aprendizagem interdisciplinar. Assim, a leitura contribui para a evolução educacional do aluno e para a sua formação de um modo geral, conforme, assevera Martins (1994, p. 25) "a leitura seria a ponte para o processo educacional eficiente, proporcionando a formação integral do indivíduo.”.

A leitura também é uma maneira do cidadão desenvolver sua opinião crítica acerca dos fatos que acontecem ao seu redor, fortalecendo o exercício da cidadania que é composta por “[...] uma série de direitos, deveres e atitudes relativos ao cidadão.” (PINSKY, 2011, p. 18).

Piúba (2012) defende que se a leitura é entendida como um direito humano que possibilita exercer a democracia, então, pode se concluir que a leitura é um direito de cidadania. O autor também frisa "que o acesso ao livro e a formação leitora seja um direito básico de cidadania, de inclusão social e de desenvolvimento.” (PIÚBA, 2012, p. 217).

\subsection{Ler na atualidade}

Os atrativos trazidos pela Internet, e com ela as mídias sociais, fizeram surgir a chamada Geração Digital (nativos digitais), que compreende a geração dos jovens leitores da atualidade. Observa-se que uma das ferramentas utilizadas pelos jovens para compartilhar assuntos literários é o Booktube que compreende um canal de vídeos dentro do Youtube. Nele os Booktubers, que são os jovens leitores e também produtores dos vídeos, compartilham suas experiências em relação aos livros lidos e outras atividades relacionadas à leitura (PAIVA; SOUZA, 2017). Outra modalidade de vídeos, que são uma extensão do Booktube e são produzidos na plataforma do Youtube, são os vlogs, para a disseminação da leitura os vloggers ou vlogueiros também produzem vídeos que são compartilhados por meio dos vlogs literários (PEREIRA; GUIMARÃES; SANTOS, 2017).

Cabe destacar que a leitura quando desmotivada não resulta em aprendizagem, conforme as palavras de Kleiman (2011, p. 35): 
A prática de leitura dos alunos da escola de educação profissional Concórdia

Cabe notar que a leitura que não surge de uma necessidade para chegar a um propósito não é propriamente leitura; quando lemos porque outra pessoa nos manda ler, como acontece frequentemente na escola, estamos apenas exercendo atividades mecânicas que pouco tem a ver com significado e sentido. Aliás, essa leitura desmotivada não conduz à aprendizagem; [...], material irrelevante para um interesse ou propósito passa desapercebido e é prontamente esquecido.

Por outro lado, caso o leitor tenha menos experiência, por meio dos objetivos de leitura impostos por outrem, visando seu desenvolvimento de forma positiva, poderá o leitor passar a elaborar suas próprias estratégias de leitura, com base no que lhe foi proposto (KLEIMAN, 2011).

Atualmente, um dos desafios é reconhecer a devida importância da leitura para a "apropriação da informação" e a "construção do conhecimento", com o intuito de formar cidadãos críticos e com autonomia para colaborar com o desenvolvimento social, organizacional e político, uma vez que a falta de capacidade para a compreensão e interpretação de um texto por parte destes cidadãos pode tornar uma sociedade passível de ser manipulada (SILVA, 2015).

\subsection{A relação do adolescente com a leitura}

De acordo com a última Pesquisa Retratos da Leitura no Brasil (2016), dentre os jovens com faixa etária entre 14 a 17 anos que declararam ser leitores, o percentual de jovens que afirmou gostar de ler foi de $48 \%$, superando o percentual de $42 \%$ que elencou a leitura como uma obrigação, contrariando também a média nacional de indivíduos que se declararam leitores, cujo percentual dos que mencionaram ler por prazer foi de $40 \%$, ao passo que, os que disseram ler para atender necessidades variadas, como por exigência para atividades relacionadas ao trabalho ou à escola, somaram 54\% (CECCANTINI, 2016).

Esses dados remontam a um panorama positivo entre os adolescentes e os jovens em relação à leitura. Gostar de ler é uma opção, no entanto, manter o hábito de leitura por prazer ao longo da vida não traz apenas benefícios ao leitor, mas seu interesse pode ser propulsor para motivar as pessoas que o cercam.

Nesse contexto, importa observar que uma das características dos jovens atuais é a sua facilidade em interagir com as Tecnologias da Informação e Comunicação (TICs), são eles os chamados nativos digitais. No entanto, embora tenham domínio dos meios tecnológicos, a 
adesão dos nativos digitais à leitura de $e$-books, que são os livros eletrônicos, ainda é baixa e predomina a preferência pela leitura de livros impressos (HELLER; MELLO JUNIOR, 2017).

Há de se considerar, também, que a escola desempenha um papel importante na disseminação de práticas de leitura que, ao mesmo tempo em que podem ser exitosas para alguns alunos, também podem ser experiências frustrantes para outros. Conforme Lourenço (2010), predomina nas disciplinas escolares um modelo tradicional de imposição de leitura de certas literaturas brasileiras seguidas de atividades para confirmar que esta foi feita, no entanto, tais atividades não instigam o aluno a ler, aumentam o desinteresse pela leitura e, com isso, a afirmação dos educadores de que "adolescentes não leem".

De outro norte, na pesquisa feita por Boto e Braz (2017), um professor pesquisado mencionou que a leitura de livros clássicos é mais importante em relação à leitura dos bestsellers por fazerem parte de questões de vestibulares e exames.

Lourenço (2010) constatou que entre os adolescentes predomina a leitura de obras de literatura de massa, que são publicadas recentemente, cujos enredos são adaptados em filmes e são traduções de literaturas estrangeiras.

Da mesma forma, a pesquisa realizada por Boto e Braz (2017, p. 681), com adolescentes que são alunos do sétimo ao nono ano do Ensino Fundamental e do primeiro ano do Ensino Médio de uma escola particular da cidade de Aracaju/SE, indicou que "entre os livros mais comprados [...] e os mais lidos e emprestados da biblioteca são os best-sellers com quase 80\% de movimentação, em comparação com os livros didáticos e os clássicos literários". A pesquisa também apontou que $62 \%$ dos adolescentes pesquisados preferem leituras sem finalidades escolares, ou seja, preferem a leitura por iniciativa própria (BOTO; BRAZ, 2017).

Destaca-se o resultado da pesquisa feita por Correia, Fragatti e Santa Clara (2017) com adolescentes matriculados no ensino médio, em que a preferência de leitura tanto de livros impressos quanto digitais foi por romances e séries, superando a preferência pela leitura dos best-sellers.

Dados obtidos em pesquisas com o público adolescente apontam que os estes gostam de ler, mesmo que o número destes leitores ainda precise melhorar. Os adolescentes preferem obras e autores atuais e populares, que não são consideradas, por exemplo, em provas de vestibulares. 


\subsection{As políticas públicas para o desenvolvimento da leitura}

Um marco para o incentivo e fomento ao livro e à leitura foi o Plano Nacional do Livro e da Leitura - PNLL, criado pela Portaria Interministerial 1.442, de 10 de agosto de 2006, do Ministério da Cultura e da Educação e, posteriormente, em $1^{\circ}$ de setembro de 2011 estabelecido através do Decreto 7.559.

Com o objetivo de estabelecer uma política pública voltada ao livro e à leitura, as diretrizes do PNLL se destinam a promover a formação de uma sociedade leitora, sendo esta uma condição contundente para a inclusão social para milhões de brasileiros (BRASIL, [201?]).

Desse modo, estabelece o art. $1^{\circ}$ do Decreto 7.559/2011 que "O Plano Nacional do Livro e Leitura - PNLL consiste em estratégia permanente de planejamento, apoio, articulação e referência para a execução de ações voltadas para o fomento da leitura no País." (BRASIL, 2011). A legislação determina que o PNLL será implementado por meio da colaboração entre as esferas federais, estaduais e municipais (BRASIL, 2011).

A instituição do Plano Nacional do Livro e da Leitura - PNLL foi um grande avanço para o incentivo de políticas públicas focadas no incentivo ao livro e à leitura. Mas, outro grande marco, foi a criação da Lei 13.696/2018, sancionada pelo Presidente da República em 12 de julho de 2018, que instituiu a Política Nacional de Leitura e Escrita - PNLE, a referida lei visa promover o livro, a leitura, a escrita, a literatura e as bibliotecas públicas no Brasil (BRASIL, 2018) e também é chamada de Lei Castilho.

A PNLE deve ser implementada pela União, através dos Ministérios da Educação e da Cultura, juntamente com Estados, Municípios e Distrito Federal, além da sociedade e de instituições privadas. Para tanto, conforme o PNLE, a cada 10 anos, deve ser desenvolvido o PNLL, com ações e metas que visam estimular a leitura (CUNHA, 2018).

Apesar da previsão legal, na prática é necessário, principalmente, que os bibliotecários e profissionais da educação, como propulsores da leitura, em conjunto com os demais entes mencionados na legislação, acompanhem e participem das ações propostas para que de fato a PNLE e o PNLL sejam efetivados.

Entretanto, pondera Marques Neto (2016) que as políticas destinadas à formação de leitores não se restringem apenas ao fornecimento de ferramentas e tecnologias em locais como 
escolas e bibliotecas, pois a real implantação de programas para a formação de leitores efetivos depende, primeiramente, de uma sociedade e um governo democráticos que tenham como objetivo o desenvolvimento da sociedade e da economia destinados a maioria da população. $\mathrm{O}$ autor ainda destaca que a busca por um maior número de leitores e de políticas voltadas para implantação de práticas de leitura será um trabalho para várias gerações e as gerações atuais não devem retroceder ao tempo em que a leitura e o livro não eram temas para políticas públicas e, tão pouco, tinham a importância que hoje possuem para os governantes.

\subsection{A família como incentivadora da leitura}

Em seu processo de formação, a criança busca como referência as atitudes de familiares e pessoas de seu convívio direto. Por isso, os pais que possuem hábitos como o de leitura influenciam diretamente no gosto de seus filhos em relação a ela (GOUVEIA, 2009).

Assim, “[...] o acesso ao livro e à leitura deveria ser estimulado na família, na escola e na biblioteca em todos os ciclos do desenvolvimento humano [...]” (MORO; ESTEBEL, 2012, p. 42). Mas, as autoras também frisam que a família não deveria adiar para a escola as funções de formação e incentivo à leitura.

Este primeiro contato com a leitura, da forma com que é feito, é a parte inicial para o processo de aprendizagem da leitura, são atitudes simples, mas que auxiliam positivamente a criança no momento da aprendizagem.

Para atrair a atenção das crianças e apresentar a leitura como uma escolha prazerosa, defendem Moro e Estebel (2012) que a família pode utilizar suportes tecnológicos para trazer à elas a "leitura lúdica" de imagens, textos pequenos, histórias interativas, entre outros recursos que os aparelhos modernos possibilitam, entretanto, sem dispensar a apresentação para as crianças de recursos bibliográficos que a família puder dispor. Pois, para o adolescente que cresceu em um contex to familiar em que o livro não esteve presente, a escolha pelo computador irá sobrepor a opção do livro, devido aos atrativos visuais, sonoros e textuais disponíveis nas mídias.

Conforme a faixa etária das crianças, a família pode disponibilizar os mais variados tipos de livros, conforme for o interesse das crianças, porém é necessário observar, além da 
quantidade, a qualidade desses livros, já que esta contribui para um melhor desenvolvimento da leitura, da oralidade e da escrita das crianças (BALÇA; AZEVEDO; BARROS, 2017).

Além de disponibilizar livros e materiais para leitura, a família também contribui para que a criança possa desenvolver a "leitura de mundo", citada por Freire (2002), através da “[...] presença de narradores e de leitores entre os familiares presentes na vida da criança e modelos de referência de leitores." (MORO; ESTEBEL, 2012, p. 57), ou seja, a convivência da criança com familiares que leem é fundamental para que ela, além de fazer o exercício de leitura de mundo, consiga desenvolver a leitura como um hábito.

As ações de leitura “[...] devem iniciar na família, implementar-se na escola e continuar no processo de vida do adulto e do idoso, por meio de políticas públicas de leitura que contemplem a bibliodiversidade.” (MORO; ESTEBEL, 2012, p. 55).

A maioria dos pais ainda não entende a importância do seu papel na apresentação e motivação da leitura aos filhos, atribuindo a responsabilidade somente para a escola e para a sociedade (BALÇA; AZEVEDO; BARROS, 2017). As autoras Martha e Neves (2012), atribuem a questões de ordem social, econômica e cultural o fato de não haver na maioria das famílias uma formação leitora e, por consequência, não há nestas a mediação de leitura refletindo na inexistência do primeiro contato da criança com a leitura no ambiente familiar.

\subsection{As bibliotecas escolares}

A existência de uma biblioteca em determinada comunidade, em tese, contribui positivamente para a aprendizagem, o lazer, a cultura e a informação. Registra-se que a biblioteca escolar é o local que pode servir como marco inicial no processo de formação de leitores.

A biblioteca escolar é compreendida como parte integrante da proposta educacional das escolas, contribuindo para o aprimoramento da educação brasileira. Logo, a atuação de cada biblioteca está vinculada à finalidade da instituição em que se encontra inserida, no caso da biblioteca escolar, esta fica localizada em uma unidade escolar e sua finalidade é contribuir para o processo de ensino-aprendizagem.

Nesse contexto, as diretrizes da IFLA/UNESCO também destacam a importância da biblioteca escolar ao contribuir para a aprendizagem e o desenvolvimento dos alunos para a 
vida adulta. (INTERNATIONAL FEDERATION OF LIBRARY ASSOCIATIONS, 2005). Logo, a biblioteca escolar proporciona à comunidade escolar o acesso à informação para complementar o conteúdo ministrado em sala de aula e ainda colabora na formação de seus alunos como futuros cidadãos conscientes em relação ao convívio em sociedade.

Ressalta-se que a apropriação do que se lê serve como uma maneira de agregar conhecimento para poder atuar criticamente na sociedade (SILVA, 2015). Como pontuam Silva e Cunha (2016, p. 46) que no tocante a formação crítica da comunidade escolar deve haver "a atuação conjunta do bibliotecário e do professor na formação de leitores e cidadãos consumidores críticos de informação".

O bibliotecário escolar precisa se inserir na comunidade escolar, além de ter conhecimento e participar ativamente das atividades curriculares, integrando a biblioteca e a escola (BICHERI; ALMEIDA JÚNIOR, 2013).

Nesse viés, a biblioteca escolar participa desde o processo de alfabetização, quando os alunos começam a aprender a ler, até o momento em que passam a ser formadores de opinião, exercendo um papel fundamental na evolução do aluno enquanto cidadão.

Diante do exposto, observa-se que formação de leitores envolve diversos agentes, dentre eles a família, a escola, e o estado com o desenvolvimento de políticas públicas direcionadas ao livro, a leitura e as bibliotecas. Os leitores, "nativos digitais" apresentam um perfil diferenciado das gerações anteriores a 1990, pois vivem em uma sociedade conectada em rede, expostos a uma diversidade de aplicativos, mídias sociais, games, séries etc., atividades que disputam atenção com a leitura. Assim, a leitura deve ser vista além de um recurso pedagógico e para isso acontecer devem-se criar estratégias que o associam ao entretenimento, ao prazer de ler.

\section{Apresentação e discussão dos resultados}

Inicialmente descreve-se o perfil do grupo estudado, na sequência, o interesse dos adolescentes pela leitura, os agentes incentivadores da leitura, os hábitos e preferências de leitura dos adolescentes e a utilização da biblioteca escolar. 


\subsection{O perfil dos adolescentes}

Quanto ao perfil dos adolescentes que responderam ao questionário, a maior parte possui entre 16 e 17 anos de idade, perfazendo 62 (38\%) e 51 (32\%) adolescentes respectivamente, conforme descrito no gráfico 1 , a maioria está cursando o $1^{\circ}(58)$ e $2^{\circ}(55)$ anos do ensino médio.

Esse grupo analisado, constitui a geração denominada de nativos digitais, jovens que convivem e se relacionam intensamente com a Internet, mídias sociais e aplicativos para as desenvolver as atividades cotidianas. Eles preferem resolver as coisas pelo click dos seus smartphones e apresentam uma visão de mundo distinta das gerações passadas. A conectividade e a facilidade de acesso as informações implicou nas dinâmicas sociais, perpassando pela educação.

Gráfico 1 - Idade dos pesquisados

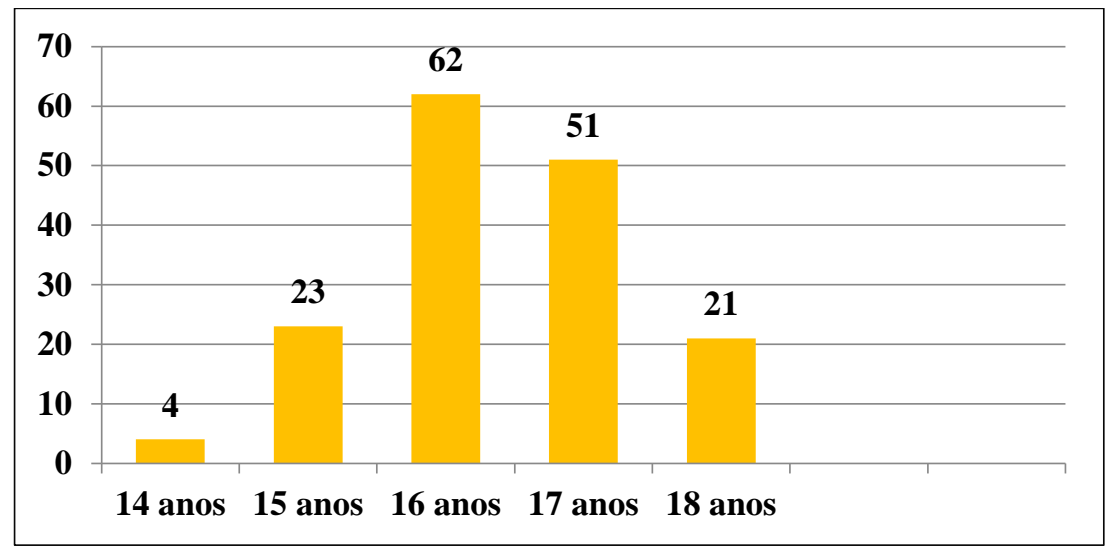

Fonte: Elaborado pelos autores (2018).

Quanto ao gênero dos respondentes, predomina o masculino com 94 (58\%) em relação ao feminino com 67 (42\%). Esse percentual masculino, está relacionado com os cursos ofertados na instituição, relacionados as áreas técnicas e às ciências exatas.

\subsection{O interesse dos adolescentes pela leitura}

Perguntados acerca do que preferem fazer nas horas vagas, os adolescentes assinalaram mais do que uma das opções listadas (gráfico 2). Dessa forma, ouvir música (97 dos pesquisados), usar WhatsApp (97 dos pesquisados) e descansar (97 dos pesquisados) foram as opções mais indicadas, seguidas do uso de Facebook e outras mídias sociais (91 dos pesquisados), atividades como reunir-se com familiares e amigos foi assinalada por 67 dos pesquisados e praticar esportes foi uma das opções assinaladas por 66 dos pesquisados, já 
assistir televisão foi uma das atividades preferidas de 42 dos adolescentes questionados. Dentre as demais atividades, a leitura de livros foi assinalada por 28 dos pesquisados e a leitura de revistas, jornais ou notícias foi sinalizada como opção por 12 dos pesquisados.

Gráfico 2 - Atividades realizadas nas horas vagas

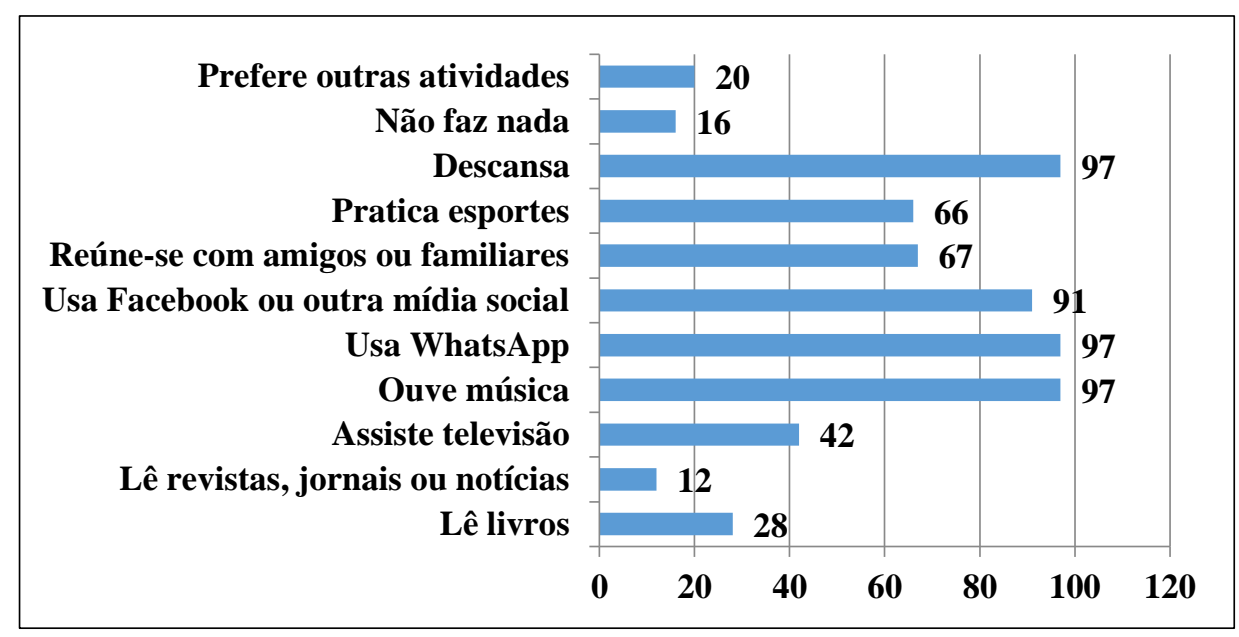

Fonte: Elaborado pelos autores (2018).

É possível vislumbrar que as mídias são muito utilizadas por esse grupo, chamados nativos digitais. Nessa perspectiva, Diniz (2016) defende que nas mídias sociais o leitor deixa de ser apenas receptor de informação, para interagir produzindo conteúdo, ademais, o autor pontua que "a forma de ler mudou, está mais interativa e a comunicação é o elemento que conecta as leituras com seus leitores, proporcionando novas práticas e hábitos de leitura." (DINIZ, 2016, p. 295).

Indagados acerca do significado atribuído à leitura, alguns adolescentes selecionaram mais de uma alternativa, assim, para 113 respondentes a leitura é uma forma de ampliar conhecimentos, 33 apontaram a leitura como uma distração, 27 assinalaram que a leitura é uma atividade prazerosa, ao passo que para 11 a leitura é uma obrigação e para 5 respondentes um aborrecimento (gráfico 3).

Apesar da maioria dos adolescentes pesquisados ter indicado que a leitura é uma maneira de ampliar conhecimentos, não é possível afirmar com veemência que tais jovens possuem plena consciência da importância da leitura para a ampliação de conhecimentos, devido a constante menção de educadores, familiares e da mídia de que a leitura é um fator essencial para a aprendizagem e para a aquisição de conhecimento. 
A prática de leitura dos alunos da escola de educação profissional Concórdia

Gráfico 3 - Significado atribuído para a leitura

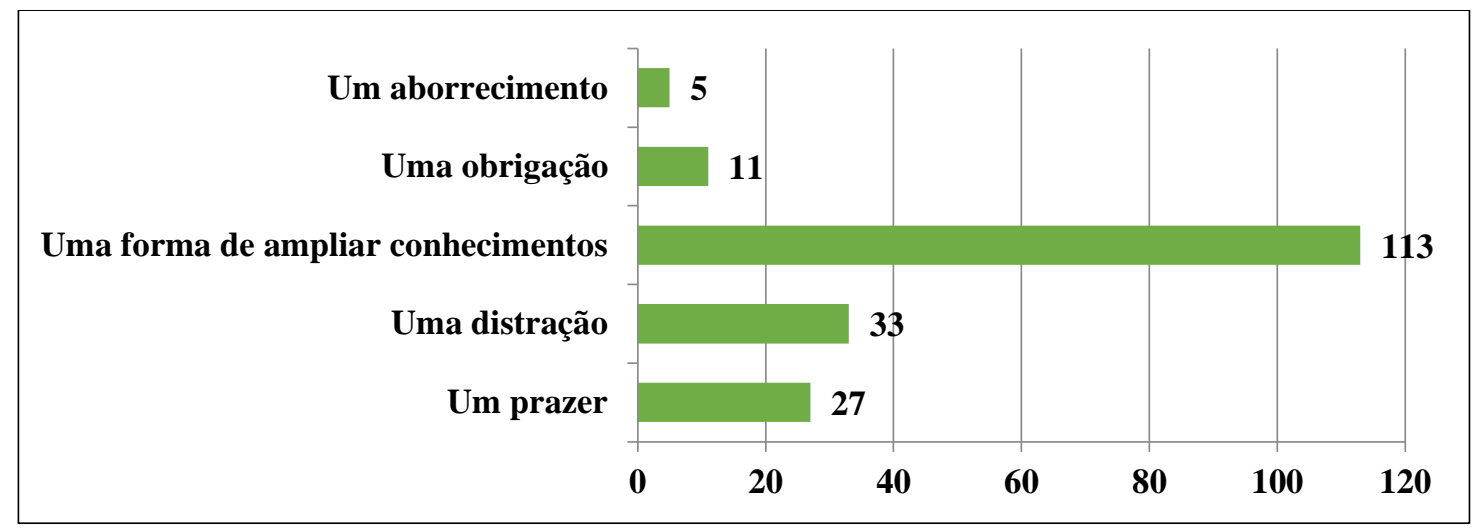

Fonte: Elaborado pelos autores (2018).

Observa-se que é um desafio tanto para professores, bibliotecários e familiares fomentar o gosto pela leitura nos jovens, tendo em vista a diversidade de entretenimento existe na atualidade (games, séries, mídias sociais). A leitura é fundamental no processo de formação e construção do indivíduo, pois contribui na construção do conhecimento e possibilita ampliar a visão de mundo.

\subsection{Os agentes incentivadores da leitura}

Um dado interessante verificado na pesquisa foi em relação ao estímulo recebido para leitura, embora tenham sido assinaladas mais de uma alternativa, a figura do professor(a) foi sinalizada por 62 dos adolescentes como sendo o agente propulsor para a motivação da leitura, seguido por 55 que apontaram a mãe como sendo a pessoa que os instigou a ler. Os demais agentes incentivadores foram: o pai com 24 indicações, uma amigo(a) ou colega com 18 indicações, o irmão(a) com 11 indicações, o bibliotecário(a) da escola com 10 indicações, outro familiar apontado por 8 respondentes, por último, o namorado(a) indicado por 1 dos adolescentes. A opção "ninguém" foi apontada por 45 dos adolescentes.

Se comparado com o resultado da pesquisa "Retratos da Leitura no Brasil 4" (FAILLA, 2016, p. 207), para a mesma pergunta, depois da opção “não/ninguém em especial”, as respostas dos entrevistados leitores e não leitores atingiram maiores resultados justamente para as mesmas figuras, ou seja, a "mãe ou responsável do sexo feminino" e "algum professor ou professora".

Foi questionado "com que frequência seus pais ou familiares liam para você antes que aprendesse a ler?", os que liam algumas vezes totalizaram o maior número que foi de 63 (39\%), 
seguido dos 47 (29\%) que liam muitas vezes, contrapondo 34 (21\%) os que liam poucas vezes e os $17(11 \%)$ que nunca liam.

Proporcionar à criança momentos de contato com a leitura, seja lendo para ela ou possibilitar que ela conviva em um ambiente em que a leitura é vista como uma atividade prazerosa, reflete em seu comportamento leitor. Em relação ao gosto pela leitura na infância (gráfico 4), 64 (40\%) indicaram que sim, gostavam de ler, 65 (40\%) afirmaram "às vezes" gostavam e $32(20 \%)$ declaram que não gostavam.

Gráfico 4 - Gosto pela leitura na infância

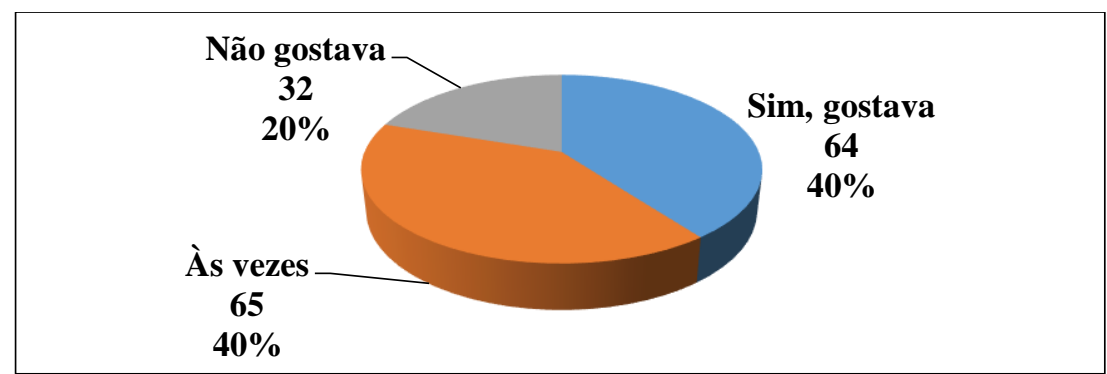

Fonte: Elaborado pelos autores (2018).

Contudo, observa-se uma dificuldade em manter o interesse pela leitura ao longo da vida. Em relação ao gosto de leitura na atualidade (gráfico 5), 33 (21\%) participantes apontaram gostar muito de ler, 99 (61\%) declararam que gostam um pouco de ler, já os que não gostavam de ler na infância $32(20 \%)$ e os que atualmente não gostam 29 (18\%), atingiram números próximos.

Gráfico 5 - Gosto pela leitura atualmente

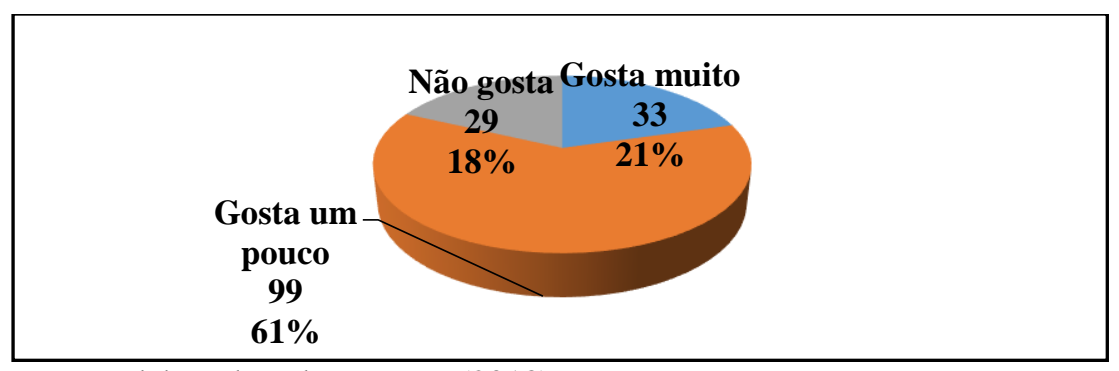

Fonte: Elaborado pelos autores (2018).

Não existe uma fórmula exata na formação de leitores, no entanto, existem estratégias para instigar a leitura nas pessoas que não possuem interesse e motivação pela mesma. Inicialmente, essas pessoas devem ser apresentadas a leitura de maneira prazerosa, ou seja, é necessário identificar que assuntos ou temas são de seu interesse, para assim indicar leituras breves, leves. Associar os textos com o seu cotidiano e a vida real, é meio de aproximação, assim como, filmes e séries. A participação em clubes de leitura ou clube de assinatura de livros 
também estimula as pessoas. Frequentar bibliotecas, livrarias e assistir à contação de histórias favorece o gosto pela leitura. No caso de crianças e jovens, usar recursos tecnológicos aliados à leitura pode ser uma alternativa, como por exemplo, leitura em e-books com animações, indicar Booktubers e vloggers. Por fim, presentear as pessoas com livros é forma de fomentar a leitura.

Balça, Azevedo e Barros (2017) enfatizam a importância da família como a primeira mediadora da leitura, mas a valorização deve continuar no ambiente escolar e acadêmico. Portanto, a leitura pode estar presente nas diversas fases da vida.

\subsection{Os hábitos e preferências de leitura dos adolescentes}

Acerca do hábito de leitura, foi indagado aos adolescentes quantos livros foram lidos nos últimos 3 meses, tal informação serve para diferenciar o indivíduo leitor e o não leitor, este critério também foi considerado na Pesquisa "Retratos da Leitura no Brasil 4". Foi definido que “Leitor é aquele que leu, inteiro ou em partes, pelo menos 1 livro nos últimos 3 meses" e "Não leitor é aquele que declarou não ter lido nenhum livro nos últimos 3 meses, mesmo que tenha lido nos últimos 12 meses.” (FAILLA, 2016, p. 184). Os resultados mostram que 46 (29\%) dos pesquisados estariam classificados como "não leitores", pois responderam que não leram nenhum livro nos últimos 3 meses, 57 (35\%) seriam considerados como "leitores" porque leram 1 livro durante o período mencionado. Há que se considerar, ainda, como "leitores" 37 (23\%) que mencionaram ter lido 2 a 3 livros, 13 (8\%) que leram 3 a 5 livros e os que leram acima de 5 livros que foram $8(5 \%)$.

Embora os adolescentes que mencionaram ter lido nos últimos 3 meses de 1 a 5 livros tenham atingido um percentual considerável e também tenham atribuído significado positivo para a leitura, com predomínio da indicação da leitura para a ampliação de conhecimento, por prazer e por distração, conforme denota-se das respostas dos adolescentes pesquisados, é possível que não o façam por apreço, uma vez que os que atualmente gostam um pouco de ler $99(61 \%)$ superam os que gostam muito de ler $33(21 \%)$.

No tocante à análise da preferência de leitura no formato impresso ou digital, averiguouse que 115 (71\%) preferem ler no tradicional suporte impresso, ao passo que 51 (32\%) preferem a leitura em plataforma digital, sendo que nesta questão alguns alunos assinalaram mais de uma opção, por isso excedeu o total de 161. 
Esta informação é semelhante ao resultado obtido na pesquisa realizada pelas bibliotecárias Correia, Fragatti e Santa Clara (2017), em que foram questionados 350 estudantes do ensino médio, com faixa etária entre 14 a 18 anos de idade, ou seja, a mesma idade do grupo analisado na presente pesquisa. Os dados indicaram que "em relação ao suporte, $61 \%$ dos estudantes ainda prefere a leitura no tradicional (impresso), $31 \%$ no digital e $8 \%$ leem nos dois tipos.” (CORREIA; FRAGATTI; SANTA CLARA, 2017, p. 893). Assim, em ambas as pesquisas, ficou evidenciado que entre o público adolescente predomina a preferência pela leitura em formato impresso. Destaca-se que não popularização dos e-readers pode influenciar essa variável.

Importa destacar que Terra (2015) afirma que a definição de um texto como literário ou não independe do suporte em que ele é difundido, mas sim a atribuição de sentido e valor conferidos por parte do leitor.

Além disso, o autor também frisa que a leitura, seja ela digital ou em material impresso, necessita de paciência, uma vez que o entendimento do que se lê por vezes não acontece de forma imediata, por esta razão é preciso ir ao encontro ao texto sem pressa, afim de que se possa “ler, reler e dialogar com o texto." (TERRA, 2015, p. 40-41).

Entre os materiais que aparecem como preferência para leitura (gráfico 6) está o livro (82), outros materiais, como por exemplo, textos de mídias sociais (54), textos da internet (50), jornais (12) e revistas (12). Nesta questão, os adolescentes também assinalaram mais de uma resposta. Embora a preferência pela leitura de livros predomine, percebe-se que a leitura de textos da internet e textos oriundos de mídias sociais juntos somam um número considerável. Segundo Terra (2015, p. 40) “[...], mesmo na era da internet, com seus hipertextos, não podemos deixar de levar em conta que estes são uma forma de texto"

Gráfico 6 - Preferência de materiais para leitura

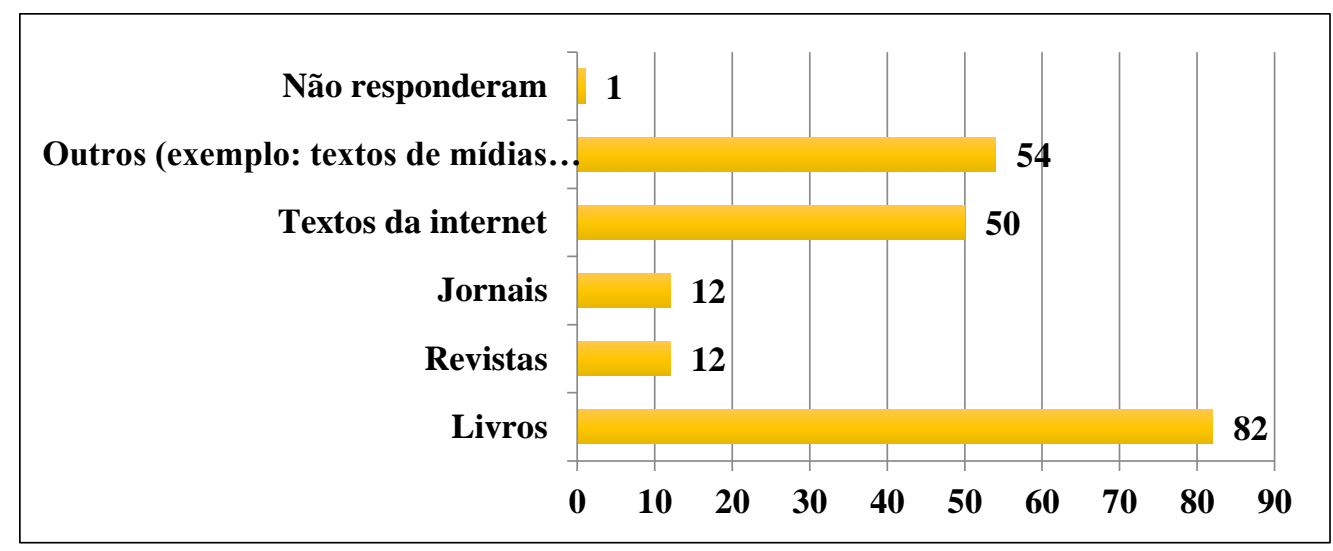

Fonte: Elaborado pelos autores (2018).

Bibl. Esc. em R., Ribeirão Preto, v. 7, n. 1, p. 57-81, 2020. 
Acerca do gênero de leitura preferido (gráfico 12), foram assinaladas mais de uma alternativa por parte de alguns adolescentes, dentre os mais citados aparecem os seguintes gêneros: ficção (76), romance (48), comédia (44), outros gêneros (34), gibis (30) e, entre os menos citados estão a bíblia (21), autoajuda (21), poesia (18), contos (17), materiais didáticos (11) e religioso (4).

Gráfico 7 - Preferência de gênero de leitura

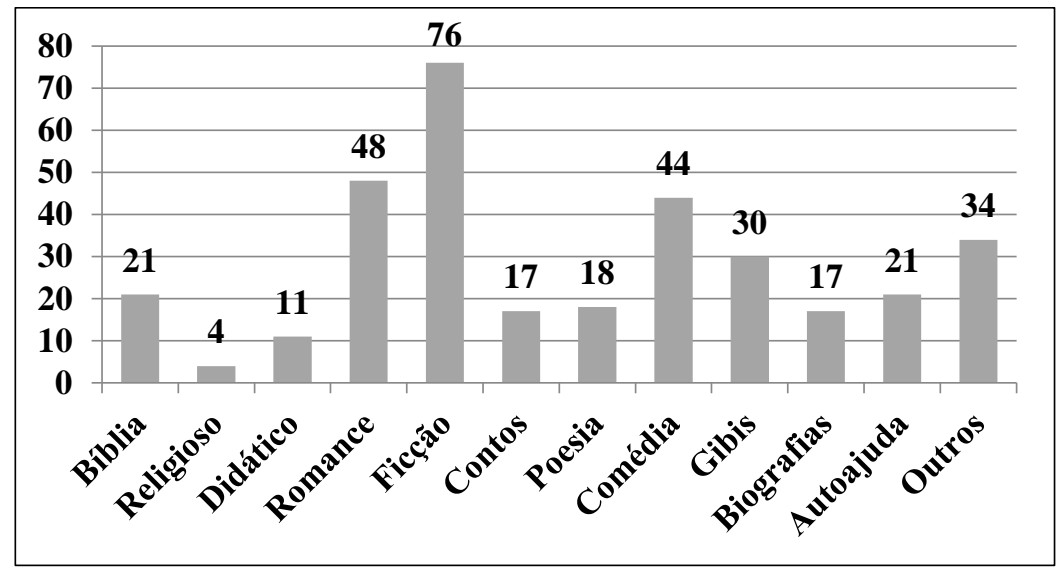

Fonte: Elaborado pelos autores (2018).

Também foi questionado qual foi o livro que marcou a vida de cada adolescente, apesar de 23 não terem respondido a pergunta, através dos títulos citados, podem ser verificadas algumas particularidades que remetem ao estilo de literatura lida pelo público em questão. Entre os títulos que foram citados mais de uma vez, podem ser destacados "O menino do pijama listrado", “A culpa é das estrelas", "O pequeno príncipe”, "Os 13 porquês”, “A última música”, "Como eu era antes de você", "Querido John”, os livros das coleções "Diário de um banana", "Harry Potter”, “A seleção", "Zac Power”, "Percy Jackson”, "Minha vida fora de série” e “Assassin'screed".

Assim sendo, observa-se nas respostas do público pesquisado que a preferência de leitura é por livros em séries, livros que foram retratados em filmes ou séries e de autores mais atuais, como por exemplo, Nicholas Sparks e Jojo Moyes. Além disso, a maior parte dos títulos citados é de literatura estrangeira traduzida. A adaptação de obras literárias em filmes ou séries compreende o processo de tradução intersemiótica que permite recodificar signos que são traduzidos em outros signos (AMORIM, 2013).

Os adolescentes indicaram sua preferência por títulos que fazem parte da "leitura de massa", inclusive, foi o mesmo resultado obtido na pesquisa realizada por Lourenço (2010, p. 376), em que os jovens apontaram como motivação a leitura de tais títulos pelo fato de serem 
“[...] fáceis de ler, leitura rápida, enredos interessantes, assistiu ao filme, considerou a capa atraente, indicação de amigos ou familiares, propagandas, identificação com a obra.”.

Ainda segundo a autora, os adolescentes leem obras que são consideradas como "leitura de massa", contrariando a afirmação por parte dos professores de que o jovem não lê, quando, na verdade, o que ele busca ler não são exatamente as obras impostas como leitura obrigatória nas escolas, por isso, as leituras por eles realizadas, de certa forma, não são vistas pela escola como leituras.

\subsection{A utilização da biblioteca escolar}

Outra informação interessante foi em relação às formas com que os adolescentes conseguem acessar livros e materiais para leitura, houve alguns questionários com mais de uma alternativa assinalada e 105 adolescentes responderam que fazem empréstimo na biblioteca da escola, 39 acessam através da compra, 36 utilizam materiais baixados da internet, 26 efetuam empréstimo na biblioteca pública, 15 emprestam materiais de amigos ou colegas, 8 assinalaram o acesso através de xerox ou digitalizações, assim como, 7 indicaram obter livros e materiais de leitura por meio de outras formas.

Conforme se denota, a biblioteca escolar figura como uma das principais formas de disponibilização de livros e materiais para a leitura. Logo, fica evidente a importância que ela possui no processo de ensino e aprendizagem, de acordo com que destacam Silva e Cunha (2016), anteriormente citados, além de que, segundo Silva (2015), a biblioteca escolar pode contribuir para a disseminação da informação de forma a desenvolver o pensamento crítico de seus usuários no tocante à sociedade em que estão inseridos.

$\mathrm{Na}$ instituição de ensino em que a pesquisa foi aplicada existe biblioteca com bibliotecário(a). Conforme confirmado pelos adolescentes pesquisados, com exceção de 1(1\%) que não respondeu a pergunta, 160 (99\%) afirmaram que a escola em que estudam há biblioteca.

Apesar disso, constatou-se que a frequência com que eles costumam ir à biblioteca não é constante, uma vez que, 12 (7\%) responderam "sempre" frequentar a biblioteca, 69 (43\%) apontaram que "às vezes" frequentam a biblioteca, 63 (39\%) admitiram que "raramente" vão à biblioteca e 17 (11\%) que "não frequentam bibliotecas". 
Importa destacar que o professor ou professora foi a figura destacada pelos adolescentes pesquisados como agente estimulador para a leitura, assim como, a maneira predominante pela qual os adolescentes acessam a livros e materiais para leitura é por meio de "empréstimo na biblioteca da escola", conforme as respostas dos adolescentes, apesar da estreita relação entre a escola e a leitura, curiosamente, a biblioteca escolar não é frequentada com assiduidade

Cunha (2012, p. 88) explica que há “[...] urgência de a biblioteca brasileira se repensar, modernizar-se com relação a acervo, espaço, pessoal e projetos, para realmente cumprir sua função de convidar à permanência e oferecer-se como lugar de leitura.”. Por isso, a biblioteca escolar precisa ser um lugar atrativo e ser entendida como parte integrante e fundamental no processo de ensino e aprendizagem para que possa receber investimentos compatíveis para atender as mais variadas demandas de materiais e serviços para seus usuários.

\section{Considerações finais}

Um dado positivo remete ao entendimento de que a maioria apontou o ato de ler como uma maneira para obtenção de conhecimento. O número dos que responderam que ler é uma atividade prazerosa e uma forma de distração é maior em relação aos que atribuíram para a leitura o significado de obrigação ou aborrecimento

Ainda que a faixa etária pesquisada faça parte de uma geração que faz uso das tecnologias e ferramentas digitais e que prefere interagir nas mídias sociais em detrimento de outras atividades, o formato impresso supera a preferência pela leitura de outros materiais no suporte digital, o que indica que apesar da praticidade oferecida pelos materiais digitais, os materiais impressos são preferência.

Mas outro dado obtido que merece ser destacado é o fato de que, se comparados com os critérios de definição de indivíduos leitores e não leitores definidos pelo Instituto Pró-Livro, os resultados da presente pesquisa, no que tange à indicação da quantidade de livros lidos nos últimos três meses, dão conta que, entre os adolescentes pesquisados, o número de leitores é maior em relação aos não leitores.

A preferência de leitura do público em voga é por leituras de obras de literatura estrangeira traduzidas que são populares, por terem sido transformadas em filmes ou séries e que possuem enredos fáceis de compreender, com os quais os adolescentes identificam-se, já 
que se tratam de inquietações frequentes neste período da vida. Inclusive, leituras nesse sentido revelam aflições pelas quais o adolescente vive e, por meio do monitoramento, por exemplo, de quais são os livros emprestados, podem servir, também, como fonte de auxílio pedagógico. Ademais, a leitura de textos e materiais extraídos da internet ou de mídias sociais, também pode ser considerada, de certa forma, como leitura, embora, às vezes, desprovida de formalidades linguísticas. Todavia, tais leituras não são mensuradas no ambiente escolar e, por isso, a impressão de que o adolescente não lê.

Inicialmente, observou-se que os professores e a figura materna possuem um importante papel como agentes incentivadores da prática da leitura na infância. A pesquisa mostrou que a maior parte dos adolescentes pesquisados teve contato com a leitura antes de aprender a ler, por meio de seus pais ou familiares. O percentual dos que apontaram gostar de ler na infância supera o percentual dos que assinalaram gostar muito de ler atualmente, logo, percebe-se a dificuldade em manter o gosto pela leitura ao longo da transição entre a infância e a adolescência.

Uma informação preocupante que a pesquisa revelou foi o fato de que muito embora exista biblioteca na escola e o modo como os adolescentes tem acesso a livros e materiais para leitura seja predominantemente por meio de empréstimos na biblioteca da escola, ela não está sendo atrativa para o público adolescente, pois, quanto à frequência de utilização da biblioteca, prevaleceu a indicação de que ela é frequentada "às vezes" e "raramente".

Com efeito, o incentivo à leitura ainda precisa ser mais bem trabalhado para que se compreenda sua importância para o desenvolvimento cognitivo do adolescente, bem como para o fortalecimento e exercício da cidadania e como forma de inclusão social. Por isso, é fundamental o esforço, por parte dos agentes envolvidos nesse processo, para instigar e fortalecer o hábito da leitura entre os adolescentes para que perdure durante a fase adulta. 


\section{Referências}

AMORIM, Marcel Alvaro de. Da tradução intersemiótica à teoria da adaptação intercultural: estado da arte e perspectivas futuras. Itinerários: Revista de Literatura, Araraquara, n. 36, p. 15-33, jan./jun. 2013.

BALÇA, Ângela Maria Franco Martins de Paiva; AZEVEDO, Fernando José Fraga de; BARROS, Lúcia Maria Fernandes Rodrigues. A formação de crianças leitoras: a família como mediadora de leitura. Revista de Educação Pública, Cuiabá, v. 26, n. 63, p. 713-727, set./dez. 2017.

BICHERI, Ana Lúcia Antunes de Oliveira; ALMEIDA JÚNIOR, Oswaldo Francisco. Bibliotecário escolar: um mediador de leitura. Biblioteca Escolar em Revista, Ribeirão Preto, v. 2, n. 1, p. 41-54, ago. 2013.

BOTO, Karolinne de Santana; BRAZ, Márcia Ivo. Práticas de incentivo à leitura para o público adolescente: um estudo sobre os best-sellers infanto-juvenis. In: CONGRESSO BRASILEIRO DE BIBLIOTECONOMIA, DOCUMENTAÇÃO E CIÊNCIA DA INFORMAÇÃO, 27., 2017, Fortaleza. Anais eletrônicos... Fortaleza: CBBD, 2017. Disponível em: https://rbbd.febab.org.br/rbbd/article/view/878/838. Acesso em: 28 nov. 2018.

BRASIL. Decreto $n^{\circ} 7.559$, de $1^{\circ}$ de setembro de 2011. Dispõe sobre o Plano Nacional do Livro e Leitura - PNLL e dá outras providências. Diário Oficial [da] República Federativa do Brasil, Brasília, 5 set. 2011. Disponível em:

http://www.planalto.gov.br/CCIVIL_03/_Ato2011-2014/2011/Decreto/D7559.htm. Acesso em: 08 nov. 2018.

BRASIL. Lei $\mathrm{n}^{\circ}$ 10.097, de 19 de dezembro de 2000. Altera dispositivos da Consolidação das Leis do Trabalho - CLT, aprovada pelo Decreto-Lei no 5.452, de $1^{\circ}$ de maio de 1943. Diário Oficial [da] República Federativa do Brasil, Brasília, 20 dez. 2000. Disponível em: https://www.planalto.gov.br/ccivil_03/leis/110097.htm. Acesso em: 22 maio 2019.

BRASIL. Ministério da Cultura. Plano Nacional do Livro e da Leitura. [201-?] Disponível em: http://www.cultura.gov.br/pnll. Acesso em: 08 nov. 2018.

BRASIL. Ministério da Cultura. Política nacional de leitura e escrita é sancionada. 2018. Disponível em: http://www.cultura.gov.br/banner-2/-

/asset_publisher/0u320bDyUU6Y/content/politica-nacional-de-leitura-e-escrita-esancionada/10883. Acesso em: 28 nov. 2018.

CECCANTINI, João Luís. Mentira que parece verdade: os jovens não leem e não gostam de ler. In: FAILLA, Zoara (org.). Retratos da leitura no Brasil 4. Rio de Janeiro: Sextante, 2016. p. 83-98. Disponível em:

http://prolivro.org.br/home/images/2016/RetratosDaLeitura2016_LIVRO_EM_PDF_FINAL COM_CAPA.pdf. Acesso em: 22 out. 2018.

CORREIA, Raquel Pinto; FRAGATTI, Poliana; SANTA CLARA, Gisele Tosi de. Preferências de leitura dos estudantes de ensino médio. In: CONGRESSO BRASILEIRO DE BIBLIOTECONOMIA, DOCUMENTAÇÃO E CIÊNCIA DA INFORMAÇÃO, 27., 2017, 
Fortaleza. Anais eletrônicos... Fortaleza: CBBD, 2017. Disponível em: https://rbbd.febab.org.br/rbbd/article/view/1013/703. Acesso em: 07 nov. 2018.

CUNHA, Maria Antonieta Antunes. O acesso à leitura no Brasil: os recados dos "retratos da leitura". In: FAILLA, Zoara (org.). Retratos da leitura no Brasil 3. São Paulo: Imprensa Oficial do Estado de São Paulo: Instituto Pró-Livro, 2012. p. 83-91. Disponível em: http://www.prolivro.org.br/images/antigo/4095.pdf. Acesso em: 07 nov. 2018.

CUNHA, Murilo Bastos da. A nova lei brasileira sobre o livro, a leitura, a escrita, a literatura e as bibliotecas públicas. Revista Ibero-Americana de Ciência da Informação, Brasília, v. 11, n. 3, p. 562-564, jul. 2018.

DINIZ, Johnathan Pereira Alves. Práticas de leitura nas mídias sociais: Influências da mídia social facebook na formação de leitores dos cursos de graduação do Instituto Federal Goiano - Campus Urutaí. In: INTERPROGRAMAS SECOMUNICA, 15., 2016, Brasília. Anais eletrônicos... Brasília: UCB, 2016. Disponível em:

https://portalrevistas.ucb.br/index.php/AIS/article/view/7866/4878. Acesso em: 04 nov. 2018.

FAILLA, Zoara (org.). Retratos da leitura no Brasil 4. Rio de Janeiro: Sextante, 2016. Disponível em:

http://prolivro.org.br/home/images/2016/RetratosDaLeitura2016_LIVRO_EM_PDF_FINAL_ COM_CAPA.pdf. Acesso em: 05 nov. 2018.

FREIRE, Paulo. A importância do ato de ler: em três artigos que se completam. 43. ed. São Paulo: Cortez, 2002.

GOUVEIA, Joana Mesquita Saldanha. Hábitos de leitura em crianças e adolescentes: um estudo de caso em alunos do segundo e terceiro ciclos do Ensino Básico. 2009. $225 \mathrm{f}$.

Dissertação (Mestre em Supervisão e Coordenação da Educação) - Universidade Portucalense, Porto, 2009. Disponível em: http://repositorio.uportu.pt/jspui/handle/11328/209. Acesso em: 25 out. 2018.

HELLER, Barbara; MELLO JUNIOR, José de. Cultura do impresso e a recepção do e-book no Brasil: Resultados de uma pesquisa quantitativa com leitores nativos e imigrantes digitais. Revista Estudios sobre las Culturas Contemporáneas, Colima, v. 23, supl. 3, p. 1-29, fev. 2017.

INTERNATIONAL FEDERATION OF LIBRARY ASSOCIATIONS. Diretrizes da IFLA/ Unesco para a biblioteca escolar. Tradução de Neusa Dias de Macedo e Helena Gomes de Oliveira. São Paulo, 2005. Disponível em: https://www.ifla.org/files/assets/school-librariesresource-centers/publications/school-library-guidelines/school-library-guidelines-pt_br.pdf. Acesso em: 25 out. 2018.

KLEIMAN, Angela. Texto e leitor: aspectos cognitivos da leitura. 14. ed. Campinas: Pontes, 2011.

KOCH, Ingedore Villaça; ELIAS, Vanda Maria. Ler e compreender: os sentidos do texto. 3. ed. São Paulo: Contexto, 2010. Disponível em:

https://unochapeco.bv3.digitalpages.com.br/users/publications/8572443274/pages/_1. Acesso em: 05 nov. 2018. 
A prática de leitura dos alunos da escola de educação profissional Concórdia

LOURENÇO, Daiane da Silva. Adolescentes leem, sim: a circulação da literatura estrangeira na escola. In: COLÓQUIO DA PÓS-GRADUAÇÃO EM LETRAS UNESP, 2., 2010, Assis. Anais eletrônicos... Assis: UNESP, 2010. Disponível em: http://www.assis.unesp.br/Home/PosGraduacao/Letras/ColoquioLetras/daianedasilva.pdf. Acesso em: 26 out. 2018.

MARQUES NETO, José Castilho. Retratos da leitura no Brasil e as políticas públicas: fazer crescer a leitura na contracorrente: revelações, desafios e alguns resultados. In: FAILLA, Zoara (org.). Retratos da leitura no Brasil 4. Rio de Janeiro: Sextante, 2016. p. 57-73. Disponível em: http://prolivro.org.br/home/images/2016/RetratosDaLeitura2016_LIVRO_EM_PDF_FINAL_ COM_CAPA.pdf. Acesso em: 22 out. 2018.

MARTHA, Alice Áurea Penteado; NEVES, Iara Conceição Bitencourt. Itinerário e Experimentação de Práticas de Leituras: propostas de intervenção pedagógica: metodologia, públicos e espaços de leitura. In: NEVES, Iara Conceição Bitencourt (org). Mediadores de leitura na bibliodiversidade. Porto Alegre: Evangraf, 2012. p. 139-157. Disponível em: http://www.ufrgs.br/sead/servicos-ead/publicacoes1/pdf/MEDIADORES_Leitura_na_Bibliodiversidade.pdf. Acesso em: 26 out. 2018.

MARTINS, Maria Helena. O que é leitura. 19. ed. São Paulo: Brasiliense, 1994.

MORO, Eliane Lourdes da Silva; ESTABEL, Lizandra Brasil. Mediadores de leitura na Família, na escola, na biblioteca, na bibliodiversidade. In: NEVES, Iara Conceição Bitencourt (org). Mediadores de leitura na bibliodiversidade. Porto Alegre: Evangraf, 2012. p. 41-63. Disponível em: http://www.ufrgs.br/sead/servicos-ead/publicacoes1/pdf/MEDIADORES_Leitura_na_Bibliodiversidade.pdf. Acesso em: 23 out. 2018.

PAIVA, Sthéfani; SOUZA, Adriana Maria de. Booktube como instrumento de disseminação da informação para a geração digital. In: CONGRESSO BRASILEIRO DE

BIBLIOTECONOMIA, DOCUMENTAÇÃO E CIÊNCIA DA INFORMAÇÃO, 27., 2017, Fortaleza. Anais eletrônicos... Fortaleza: CBBD, 2017. Disponível em:

https://rbbd.febab.org.br/rbbd/article/view/794/858. Acesso em: 28 nov. 2018.

PEREIRA, Gleice; GUIMARÃES, Rachel Cristina Mello; SANTOS, Gilcelene Pereira dos. Vlogs literários: o incentivo à leitura por meio da mídia social digital Youtube. Revista Informação@Profissões, Londrina, v. 6, n. 2, p. 77-93, jul./dez. 2017.

PINSKY, Jaime. Cidadania e educação. 10. ed. São Paulo: Contexto, 2011. Disponível em: https://unochapeco.bv3.digitalpages.com.br/users/publications/9788572440905/pages/19. Acesso em: 23 out. 2018.

PIÚBA, Fabiano dos Santos. Por uma leitura dos "retratos": desafios para o desenvolvimento social da América Latina. In: FAILLA, Zoara (org.). Retratos da leitura no Brasil 3. São Paulo: Imprensa Oficial do Estado de São Paulo: Instituto Pró-Livro, 2012. p. 214-226.

Disponível em: http://www.prolivro.org.br/images/antigo/4095.pdf. Acesso em: 22 out. 2018. 
SILVA, Elaine. A contribuição da biblioteca escolar na formação de leitores enfocando o desenvolvimento individual e organizacional. Biblioteca Escolar em Revista. Ribeirão Preto, v. 3, n. 2, p. 15-30, abr. 2015.

SILVA, Judson Daniel Oliveira da; CUNHA, Jacqueline de Araújo. O papel educativo da biblioteca escolar no contexto do Plano Nacional de Educação. Revista Encontros Bibli: revista eletrônica de Biblioteconomia e Ciência da informação, Florianópolis, v. 21, n. 46, p. 45-58, maio/ago., 2016.

TERRA, Ernani. A produção literária e a formação de leitores em tempos de tecnologia digital. Curitiba: Intersaberes, 2015. 